Proceedings

\title{
Implications and solutions for municipal solid waste manage- ment: Surge in household waste arising from increased online shopping during the COVID-19 pandemic
}

\author{
Saeed Siyal * and Chunlin Xin *
}

Publisher's Note: MDPI stays neutral with regard to jurisdictional claims in published maps and institutional affiliations.

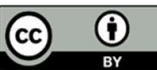

Copyright: (C) 2020 by the authors. Submitted for possible open access publication under the terms and conditions of the Creative Commons Attribution (CC BY) license (http://creativecommons.org/licenses/by/4.0/).

\begin{abstract}
Introduction: The COVID-19 pandemic is the most serious health concern currently, which emerged from China and has spread to several other countries worldwide. Besides millions of deaths, this pandemic has exposed the world to multiple problems. Methods: Of these, we seek to investigate the implications and solutions for managing municipal solid waste and the surge in household waste arising from increased online shopping in response to the current outbreak. In addition, we discuss two important research questions that will be beneficial for government and waste management officials to effectively manage municipal solid waste and household waste during the pandemic situation as well as in normal circumstances. Results: The findings revealed that the government and waste management authorities systems of managing the waste have been disturbed which have caused increase in the waste. Moreover, the increased online shopping has also resulted in increased waste production. This is a serious problem for the health and safety of the citizens which needs serious attention of the government and waste management authorities. Discussion: This study has discussed two principle questions and also recommended several implications and solutions which may be effectual for the government as well as authorities responsible for waste management.
\end{abstract}

Keywords: COVID-19; municipal solid waste; household waste; online shopping

\section{Discussion questions}

1. How do you manage municipal solid waste during lockdowns arising from the COVID-19 pandemic?

2. How do you control the increase in household waste due to increased online shopping during the lockdowns arising from the COVID-19 pandemic?

\section{Introduction}

The coronavirus disease (COVID-19) was first diagnosed in China in early December 2019, when health-care authorities were closely monitoring some cases of pneumonia-like illness in Wuhan, the capital city of China's Hubei province. The pathogen causing viral pneumonia in affected individuals is the newly recognized coronavirus - known as the severe acute respiratory syndrome coronavirus 2 (SARS-CoV-2)-due to its symptoms resembling that of the SARS epidemic, which occurred some years prior. This virus had caused approximately 2,700 deaths across the world by the end of February 2020 (World Health Organization, 2020). More than 80,000 coronavirus cases had been detected in China by early March 2020. In addition, more than 10,000 cases were also detected in approximately 72 other countries during that initial period. The number of cases continued to increase rapidly in China as well as other countries across the globe. The increasing trend of cases led to the lockdown of Wuhan and its nearby cities in early February 2020. 
The whole city was completely locked down such that no one was able to enter or leave the city and all its markets, offices, schools, colleges, universities, and transport systems were closed.

The COVID-19 pandemic has become the world's largest health calamity of the 21st century. The report of the World Health Organization (as at May 4, 2020) states that the number of people with COVID-19 is about 3,580,167 and the death rate has reached 248,450 across the world. Epidemiological forecasts indicate that this outbreak is also likely to become a serious concern even for countries with advanced and well-equipped health-care systems (Ferguson et al., 2020). Several countries have enforced pandemic preventive measures in the form of lockdowns as well as quarantines at the individual and community levels to mitigate the spread of this virus. Moreover, in response to staggering projections, intensive attention is being dedicated to the research and development of vaccines, drugs, and antivirals for COVID-19 by many institutions and countries worldwide, with the World Health Organization, China, the US, Pakistan, Thailand, etc., being in the frontline of this endeavor.

Current lockdown situations in most countries have caused people to choose online shopping to buy household and other essential goods for their normal use. In addition, people are not allowed to leave their homes, which makes it difficult to dispose off their household waste as they used to do under normal conditions. The hindrances in disposing off waste and increased online shopping has led to a surplus of waste being stored at home, which may cause problems. This is a serious concern worldwide, which requires critical attention seeking resolution. Accordingly, we choose to study two principle research questions due to their importance in the current pandemic scenario. The questions are: "How do you manage the municipal solid waste (MSW) during lockdowns arising from the COVID-19 pandemic?" and "How do you control the increase in household waste due to increased online shopping during the lockdowns arising from the COVID19 pandemic?" Answering these questions will be help to deal with the current situation and provide implications and solutions with respect to the management of MSW and the surplus waste arising from the increase in online shopping during the pandemic.

\section{Crises caused by the emergence of COVID-19}

In contrast to the extensive global growth and development in the past, the world is experiencing a severe crisis due to the COVID-19 pandemic. This pandemic has spread to many countries of the world and has caused deaths in the hundreds of thousands and infections in the millions across all age groups, with the majority of cases being among the aged and less so among children. Several countries have imposed lockdowns and curfews, leading to the closure of markets, businesses, and offices, which in turn has affected sustainable production and consumption patterns. This has made it difficult for people to obtain the goods used to sustain their survival and normal routines. It is the most serious health crisis currently, which is still in an early phase in numerous countries and is constantly evolving. Governments and health organizations have recommended the adoption of a lifestyle that includes self-quarantine and social distancing practices, to face this challenging situation and avoid the loss of human lives from this invisible infectious disease. The social distancing actions recommended by governments include avoiding huge gatherings, working from home, starting online classes and sending students back home from their hostels and dormitories, avoiding traveling and avoiding visiting markets and stores. The economic activities of all countries are also being affected by the suspended production, supply, imports and exports, thereby creating a global economic disaster (World Trade Organization, 2020). Widespread lockdowns and slowdown in economic activities and stock markets has suspended enterprise in many industries leading to high unemployment worldwide since the emergence of COVID-19. Specifically during March and April 2020, the labor category on daily wages lost their earnings, whereas salaried staff who could work from home continued to receive salaries, partially in some cases, or in full. The extant literature testifies to crises, such as wars, scarcities and deprivations, 
food scandals, and epidemic situations that have influenced institutions and society over short or long terms (Polanyi, K., 1944; Mazier, J., M. Baslé, and J.-F. Vidal., 1999; Parker. G. (2013). The financial collapse of 2008 is one of the exemplary incidents that caused variations in regulations, technology, and culture to address the deficiencies triggered by that crisis. Several countries invested largely in the related stimulus package, including China, which made a significant investment in renewable energy and triggered the growth and development of those industries, as well as a reduction in the costs of production that profited companies and communities across the globe (Zhang, D., Cao, H., and Zou, P. (2016).

These are some of the issues caused by the COVID-19 pandemic, which need timely action to provide relief to the general population. In our current discussion, we mainly focus on the management of MSW and the problem of surplus household waste arising from the increased online shopping behavior of people during lockdown. This relates to social problems also. We aim to identify the implications and develop solutions to manage MSW and household waste. For this, we have identified two principle research questions as already mentioned, to propose a conceptual understanding of the problems and set a foundation toward a broader transition.

\section{Municipal solid waste and online shopping}

MSW management is becoming a serious problem due to rapid economic growth and development, and increasing urbanization around the world (Chong, Y.T., Teo, K.M., Tang, L.C., 2016), specifically in developing nations, such as China (Cheng, H., Zhang, Y., Meng, A., Li, Q., 2007; Wang Y.Q et al., 2018). Since the reform and opening up of China in 1978, its per capita income increased which led to an increase in environmental pollution due to a rapid increase in waste generation. Based on the China Statistical Yearbooks, MSW generation was about 109 million tons in 1997, and 164 million tons in 2011, representing an increase of more than $50 \%$, which led to a rise in environmental development issues and threats (United States Environmental Protection Agency, 2013). By 2016, the quantity of MSW arising from more than 214 cities in China was estimated at 188.5 million tons (Ministry of Environmental Protection of China, 2017). This is a significant amount that causes major social, environmental and pollution concerns, and hinders the sustainable growth and development of China (Cheng \& Hu, 2010). Hence, the Chinese government is taking serious actions to strongly support MSW management to mitigate social and environmental concerns and lead the country toward smooth and sustainable development (Cheng, H., Hu, Y., 2010). MSW management systems comprise numerous elements, including MSW generation, separation, collection, transfer and transport, along with the handling and recycling processes, followed by its final disposal (Tong, X., Tao, D., 2016; Wu, J., Zhang, W.Q., Xu, J.X., Che, Y., 2015).

Addressing the challenges of MSW management systems and surplus household waste arising from increased online shopping has attracted the attention of researchers, and the government, which encourages citizens to minimize MSW generation (Zhang, W., Che, Y., Yang, K., Ren, X., Tai, J., 2012). There are two main methods of MSW disposal, i.e., incineration and landfill, both of which have different characteristics during their operational processes. Once incineration power plants are built, the operating costs can be covered by government subsidies. Alternatively, incomes received from selling the power generated can also cover expenses. In contrast, the government needs to cover expenses incurred in the operation and routine maintenance of landfill sites. Indeed, there are unambiguous contextual differences in managing MSW and household waste at all the levels, i.e., among countries, regions, cities, different communities, households and individuals also. However, due to this pandemic, the problem exists everywhere in the world regardless of whether countries are considered to be developed or developing nations. The pandemic has increased online shopping trends due to the complete shutdown of markets and malls, which has led to a surplus of MSW and household waste. For example, per the statistics of Bio Energy Consult (last updated on February 16, 2020), the situation 
of solid waste management in Pakistan is a problem of grave concern. Over 5 million people lose their lives due to diseases caused by waste. Annually, waste generation in Pakistan is more than 20 million tons with a growth rate of nearly 3\%, annually. Waste has increased exponentially during the COVID-19 pandemic, whereby cities are locked down and waste collection systems are not operational, which is likely to cause more diseases and deaths. In addition, the increased rate of online shopping results in increased solid waste generation.

Online shopping first appeared in 1994, and has since completely reshaped the purchasing system to its current form (Lewis, P.H., 1994). This term was totally unknown in the past couple of decades, but in current times it has become an essential part of human lives. Online shopping is being practiced in almost every part of the globe: for instance, one third of the US is engaged in online shopping (Walker Sands, 2017), more than 70\% of people in China use online shopping (Xiao Hui Gao, Lifeng Wu, (2018), and about 70\% of Internet users use online shopping in Pakistan (Rehman, S. U., Bhatti, A., Mohamed, R., \& Ayoup, H., 2019). These percentages have increased exponentially during the COVID19 pandemic. According to (Weltevreden, J.W.J., Rietbergen, T.V., 2007), when online shopping is used more frequently, it is less likely for people to get involved in offline shopping and visit stores and malls to buy goods they need because they can easily order and receive them at their door step. Online shopping has a lasting impact on the offline purchasing patterns of society, reduces vehicle traffic, and generally promotes e-commerce. The American Times Use Survey data of 2016 revealed that more than 14\% of the day time traffic and trips are due to shopping in stores, markets and malls, which is likely to reduce when people turn to online shopping to purchase their daily necessities.

More recently, the number of online buyers and the spend on online shopping has increased due to the current pandemic situation. People who never shopped online before are now doing so for several reasons. The reasons for not shopping online include difficulty of use, unavailability of the Internet, insufficient knowledge of online shopping and online payments via internet or mobile banking, financial risk, and lack of trust in online shops and their quality of goods. Eventually, the extent of online shopping to meet consumers' needs directly influences the amount they spend on purchases online, and this may differ from one country to another country. Online shopping platforms are very convenient, each with unique features and capabilities focused on processes that users prefer for making their online purchases. Online shops and retailers keep updating their systems and altering them per suggestions of frequent shoppers. Online sellers seek to intimately understand and incorporate what motivates consumers to buy online, which may range from the policy, technology, marketing style or the designs of their web portals.

In the current era of globalization, online shopping is expanding rapidly, and this is also happening in Pakistan. Online shopping has been continuously growing and developing, such that new portals are opened wherein individuals, retailers and organizations can easily conduct their business activities in cyberspace to expand their footprints and platforms beyond geographical limits. There are several trusted global online shopping retailers and organizations used by the consumers in Pakistan, including Amazon, eBay, Taobao, and Alibaba. Besides these there are various domestic online shopping platforms used in Pakistan that are also well-known, such as Daraz, Juniba, Chase Value Centre, Vmart, Telemart, Homeshopping and Shophive. People use these platforms to buy goods online and receive them at their doorstep. Furthermore, the evolution and development of cyberspace has been uninterruptedly improving the utilitarian as well as hedonic characteristics of internet usage. Its environment has evolved interactively in addition to being entertaining, which meets the demands of consumers to purchase the goods and services of their choice, as well as satisfies their emotional needs. Consequently, the cyberspace environment promotes and increases online shopping and strengthens the relationship between consumers and online retailers or platforms (Lee, H. S. S., Balaji, M. S., \& Khong, K. W. (2015). 
The rising popularity and acceptance of online shopping has attracted more consumers to make more purchases online during the lockdowns arising from the COVID-19 pandemic. Consumers are obtaining all the goods required for their survival and daily use from the above-mentioned online shopping portals. Buying goods online fulfills their needs and deters them from going outside, which may be harmful for their health, and in this way people can easily stay in their homes as suggested by health departments and the World Health Organization. Hence, increased online shopping increases the production of MSW and household waste, which is a serious issue for people. They face problems in managing the MSW and household waste due to the lockdown situation and no permission to go outside in public places. During normal circumstances, people go outside to dispose off their waste in boxes placed by the government in dedicated places, in other cases the government provides bags to the public to collect waste and hand it over to collection vehicles that circulate at certain times during the week. During lockdowns, no such arrangements have been made by the government for the collection of MSW and household waste, nor for its subsequent disposal. This provides us with the opportunity to seek answers to the two research questions previously mentioned, to provide relief and solutions to the common people who are already suffering from several problems with respect to their lives, health, education, jobs, and businesses. Answering these questions will be useful for government officials to assist people in solving the challenges with respect to the management and disposal of MSW and household waste.

\section{Method and Data}

Methods used in the current research are the secondary data from the current literature related to the studied variables. Several research articles related to the keywords of the study, such as municipal solid waste, implications and solutions for waste collection, disposal and recycling, online shopping, COVID-19 were studied in depth to draw the outcomes of the current research. In addition, we interviewed the citizens and government officials responsible for waste collection, disposal and recycling of the municipal solid waste. We selected five main cities of the Sindh province of Pakistan which include Dadu, Sukkur, Larkana, Hyderabad and Karachi. Out of these cities, we interviewed from 10 citizens and two officials of each city who were responsible for the municipal solid waste collection, disposal and recycling. The citizens were approached using personal contacts and were requested to participate in the data collection for the purpose of academic research, while the officials were approached by visiting their offices and giving briefing about the purpose of data collection. They were assured for the confidentiality of their personal information. They were asked the two important research questions of this research and were assured for the confidentiality of their particulars. The total number of responses was 6 which included 50 citizens and 10 officials. In fact we didn't ask or note the name or designation of any citizen or official which may show his particulars and identify the response. After collecting the data which took about six weeks of time, we draw the findings and recommend some useful implications and solutions based on their responses which may be constructive for governments and officials responsible for waste management.

\section{Discussion, implications, solutions and results}

This study offers several implications for government and waste management officials, which may be conducive to improving the collection and disposal of MSW and household waste in general, and in particular during the COVID-19 pandemic. First, the process of waste collection and disposal requires costly transportation, which is more difficult to budget for by developing countries than developed ones. After waste collection, comes screening for the separation of recyclable waste and disposal of the rest, which ends up in storage in a dump. The results of this study recommend that the government and officials design such a strategy for the proper operation and functioning of this entire process. Second, it is highly recommended to focus on low-income areas and communities 
that are not able to afford waste collection charges. This is because these low-income communities often look for vacant lots, public spaces or even ponds and lakes to dispose off their waste, to avoid paying waste collection charges. This may spread filth to neighboring places and result in diseases. Furthermore, uncollected waste is likely to block the drainage systems during rainfall and cause effluent water to run in the streets. The waste thrown in ponds may run-off into the sea or rivers, which in turn may adversely affect surrounding ecosystems. As such, this public and vulnerable dumping of solid waste may lead to diverse environmental and health hazards. Third, as people are not allowed to go outside during lockdowns, the excess storage of waste in homes may be harmful to their lives or cause certain diseases. Organic substances may decompose and discharge methane gas, which is explosive and may lead to destructive fires and the loss of human lives. Thus, it is recommended to make arrangements for the timely collection and disposal of the waste that is harmful to human lives. Fourth, food residues and kitchen waste attract flies, rats, and reptiles that may spread diseases in homes where this excess waste is being stored over a long period. Timely collection of waste is beneficial for the general population and effective in avoiding the spread of several diseases. Fifth, in response to pandemic contingencies, in the process of garbage collection and transportation, we recommend the use of non-contact intelligent collection equipment and antimicrobial disinfectants, including buried garbage collection equipment, and unmanned transportation vehicles. In doing so, the problem of surface utilization can also be solved, besides which it is an environmentally friendly procedure useful for the development of sustainability in urban areas. Hence, activities and infrastructure that are challenging and problematic and less profitable for installation on the surface can easily be shifted underground freeing up aboveground space, which can be used for other purposes. This also enhances and improves the living conditions of the people. Waste management via developed and underground infrastructure may be regarded as an essential evolution needed in modern society.

Our research proposes some useful solutions for the management of MSW and household waste during lockdowns arising from the COVID-19 pandemic, which may also be useful in normal circumstances. As surplus household waste and MSW are currently serious problems in the myriad ways discussed above, they require certain solutions. Some of the solutions include: First, the government should design strategies to collect waste from all communities regularly and timeously to avoid excess storage of waste in homes, which may be harmful to human lives in the many ways mentioned above. Moreover, the collection process must be transparent to avoid missing waste collection arrangements. Second, the recycling of waste is important and useful. It may prevent the disposal of waste that could be reused. It is typical that a portion of waste marked for disposal can be of use after proper and sterile recycling. Third, after waste recycling, the remaining waste that is ready for disposal should be taken to disposal sites without any delay. Transportation for such disposal needs to be scheduled in advanced in order to avoid delays. Fourth, the bins distributed for waste collection in public places should also be emptied while collecting waste from the surrounding communities, as excess and delayed storage of waste within such bins may cause infections to spread in the neighboring populations. Fifth, the timely disposal of landfills is also important to avoid the spread of diseases and filth in public places.

\section{Conclusion}

Currently, we are in the midst of lockdowns arising from the COVID-19 pandemic, which has placed societies on pause. This pause in turn has given rise to several problems. Among these, the management of MSW and household waste is one of the important problems experienced by communities at present. The collection systems by the government and waste management authorities are also suspended in this situation, which combined with increased online shopping, has increased the generation of waste more than 
during normal circumstances. This study provides solutions and implications for the management of solid and household waste. We have discussed the two principle research questions proposed, and provided several useful implications and solutions which may be constructive for governments and officials responsible for waste management.

Conflicts of Interest: There is no conflict of interest.

Ethics Statement: This article does not contain any studies involving human participants performed by any of the authors.

Consent Statement: The data was obtained from the participants with their consent.

Funding: This research was supported by National Key Research and Development Program of China (No. 2019YFC1906102), and National Key Technology Research and Development Program of the Ministry of Science and Technology of China (No. 2015BAK39B00).

\section{References}

ATUS, 2016. https://www.bls.gov/tus/datafiles_2016.htm.

https://www.bioenergyconsult.com/solid-waste-management-in-pakistan/accessed on May, 04,2020.

Cheng, H., Hu, Y., 2010. Curbing dioxin emissions from municipal solid waste incineration in China: re-thinking about management policies and practices. Environ. Pollut. 158, 2809-2814.

Chen, X.D., Geng, Y., Fujita, T., 2010. An overview of municipal solid waste management in China. Waste Manage. 30, 716-724.

Cheng, H., Zhang, Y., Meng, A., Li, Q., 2007. Municipal solid waste fueled power generation in China: a case study of waste-to-energy in Changchun city. Environ. Sci. Technol. 41, 7509-7515.

Chong, Y.T., Teo, K.M., Tang, L.C., 2016. A lifecycle-based sustainability indicator framework for waste-to-energy systems and a proposed metric of sustainability. Renew. Sustain. Energy Rev. 56, 797-809.

Ferguson NM, Laydon D, Nedjati-Gilani G, Imai N, Ainslie K, Baguelin M, Bhatia S, Boonyasiri A, Cucunubá Z, Cuomo-Dannenburg G, Dighe A, Dorigatti I, Fu H, Gaythorpe K, Green W, Hamlet A, Hinsley W, Okell LC, van Elsland S, Thompson H, Verity R, Volz E, Wang H, Wang Y, Walker PGT, Walters C, Winskill P, Whittaker C, Donnelly CA, Riley S, Ghani AC. Impact of non-pharmaceutical interventions (NPIs) to reduce COVID-19 mortality and healthcare demand. COVID-19 Reports, Faculty of Medicine, Imperial College, London, UK 2020; doi:10.25561/77482.

Lee, H. S. S., Balaji, M. S., \& Khong, K. W. (2015). An investigation of online shopping experience on trust and behavioral intentions. Journal of Internet Commerce, 14(2), 233-254. doi:10.1080/15332861.2015.1028250.

Lewis, P.H., 1994. Attention Shoppers: Internet Is Open. The New York Times.

Mazier, J., M. Baslé, and J.-F. Vidal (1999). When Economic Crises Endure. New York: M. E. Sharpe.

Ministry of Environmental Protection of China, 2017. National large and medium cities annual report on prevention and control of environmental pollution by solid wastes 2017. http://trhj.mee.gov.cn/gtfwhjgl/zhgl/201712/P020171214496030805251.pdf.

Parker. G. (2013) Global Crisis: War, Climate Change and Catastrophe in the Seventeenth Century. New Haven, CT: Yale University Press.

Polanyi, K. (1944). The Great Transformation: The Political and Economic Origins of Our Time. Boston: Beacon Press.

Rehman, S. U., Bhatti, A., Mohamed, R., \& Ayoup, H. (2019). The moderating role of trust and commitment between consumer purchase intention and online shopping behavior in the context of Pakistan. Journal of Global Entrepreneurship Research, 9(1), 43.

Tong, X., Tao, D., 2016. The rise and fall of a "waste city" in the construction of an "urban circular economic system": The changing landscape of waste in Beijing. Resour. Conserv. Recycl. 107, 10-17.

U.S.EPA (2013). Non-hazardous waste management hierarchy. http://www.epa.gov/osw/nonhaz/municipal/hierarchy.html Accessed 25 April 2020.

Walker Sands, 2017. Online shopping frequency of internet users in the United States as of March 2017. Statista - The Statistics Portal. Wang, Y.Q., Zhang, X.H., Liao, W.J., Wu, J., Yang, X.D., Shui, W., Deng, S.H., Zhang, Y.Z., Lin, L.L., Xiao, Y.L., Yu, X.Y., Peng, H., 2018. Investigating impact of waste reuse on the sustainability of municipal solid waste (MSW) incineration industry using emergy approach: A case study from Sichuan province, China. Waste Manage. 77, 252-267.

Weltevreden, J.W.J., Rietbergen, T.V., 2007. E-shopping versus city centre shopping: the role of perceived city centre attractiveness. J. Econ. Social Geogr. 98 (1), 68-85.

WHO. 2020. Coronavirus disease 2019 (COVID-19): situation report, 36

World Trade Organization (WTO) (2020) Trade set to plunge as COVID-19 pandemic upends global economy. Press Release, April 8, (https://www.wto.org/english/news_e/pres20_e/pr855_e.htm).

Wu, J., Zhang, W.Q., Xu, J.X., Che, Y., 2015. A quantitative analysis of municipal solid waste disposal charges in China. Environ. Monit. Assess. 187, 1-10. 
Xiao Hui Gao, Lifeng $\mathrm{Wu}$, (2018) "Using fractional order weakening buffer operator to forecast the main indices of online shopping in China", Grey Systems: Theory and Application, https:// doi.org/10.1108/GS-08-2018-0036

Zhang, W., Che, Y., Yang, K., Ren, X., Tai, J., 2012. Public opinion about the source separation of municipal solid waste in Shanghai, China. Waste Manage. Res. 30, 1261-1271.

Zhang, D., Cao, H., and Zou, P. (2016). Exuberance in China's renewable energy investment: rationality, capital structure and implications with firm level evidence. Energy Policy, 95, 468-478. 